\title{
Minimally invasive surgery for congenital diaphragmatic hernia: a meta-analysis
}

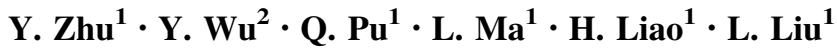

Received: 21 June 2014/ Accepted: 12 September 2015/Published online: 5 October 2015

(C) The Author(s) 2015. This article is published with open access at Springerlink.com

\begin{abstract}
Objectives To compare the safety and efficacy of minimally invasive surgery (MIS) with traditional open surgical approach for congenital diaphragmatic hernia (CDH).

Methods A literature search was performed using the PubMed database, Embase, and the Cochrane central register of controlled trials using a defined set of criteria. The outcomes, which include post-operative mortality, incidence of hernia recurrence, rates of patch use and complications, were analyzed.

Results We investigated nine studies, which included 507 patients. All studies were non-randomized historical control trials. The MIS group had a significantly lower rate of post-operative death with a risk ratio of 0.26 [95\% confidence interval (CI) $0.10-0.68 ; p=0.006]$ but a greater incidence of hernia recurrence with a risk ratio of 3.42 (95\% CI 1.98-5.88; $p<0.00001$ ). Rates of prosthetic patch use were similar between the two groups. Fewer cases of surgical complications were found in the MIS group with a risk ratio of 0.66 (95\% CI 0.47-0.94; $p=0.02$ ).

Conclusions MIS for CDH repair is associated with lower post-operative mortality and morbidity compared with traditional open repair. Although rate of patch use appears to be comparable, the increased risk of $\mathrm{CDH}$ recurrence
\end{abstract}

L. Liu

lunxu_liu@aliyun.com

1 Department of Thoracic Surgery, West China Hospital, Sichuan University, No 37, Guo Xue Xiang, 610041 Chengdu, People's Republic of China

2 Department of Pediatric Surgery, West China Hospital, Sichuan University, 610041 Chengdu, People's Republic of China should not be ignored. The lack of well-controlled prospective trials still limits strong evaluations of the two surgical techniques.

Keywords Congenital diaphragmatic hernia - Minimally invasive surgery $\cdot$ Meta-analysis $\cdot$ Hernia recurrence

\section{Introduction}

Congenital diaphragmatic hernia $(\mathrm{CDH})$ is a congenital defect in diaphragm development, which occurs in approximately 1 in 2500-4000 live births [1]. Surgical repair via laparotomy or thoracotomy is the traditional treatment for patients with $\mathrm{CDH}$. Since the first report by Silen et al. on thoracoscopic CDH repair in an adolescent in 1995 [2], minimally invasive surgery (MIS) techniques, both laparoscopic and thoracoscopic, have been considered as alternative approaches for $\mathrm{CDH}$ repair. However, this new technique has not gained widespread acceptance among surgeons mainly because of the controversy involving its safety and efficacy, such as mortality, recurrence rate and complication rate.

To compare the safety and efficacy of MIS with traditional surgical approach for $\mathrm{CDH}$, we performed an appropriate meta-analysis of the related studies.

\section{Methods}

Studies that met all the following criteria were included in the meta-analysis: (1) the trial was a randomized or nonrandomized clinical trial; (2) the study was designed to compare surgical outcomes of neonates with $\mathrm{CDH}$ between MIS intervention and open procedures; and (3) data on 
incidence of mortality, recurrence, patch use, and surgical complication rate were fully or partially reported.

We performed a literature search of the PubMed database (National Library of Medicine, Bethesda, MD, USA) that covered the period from 1966 to December 2013. The search conducted for Embase and the Cochrane Central Register of Controlled Trials was restricted to Englishlanguage literature. We applied the following subject heading or keywords: "congenital diaphragmatic hernia (CDH)", "thoracoscopy", "endosurgery", "mortality", "recurrence", "patch", and "complications". Two authors (Zhu and $\mathrm{Wu}$ ) independently performed an electronic database search to identify studies that met the eligibility criteria. Reference lists of relevant textbooks, review articles, and abstracts of scientific meetings were also included in the search.

We extracted data from each eligible study, including general information, post-operative mortality, incidence of hernia recurrence, rates of patch use, and complications.

Review Manager 5.0, which was created by the Cochrane Collaboration for meta-analysis (http://www. cochrane.org), was used for statistical analysis. Heterogeneity among studies was assessed using Cochran's Q statistic to determine whether a fixed $(p>0.1)$ or random $(p<0.1)$ effect model should be used. Dichotomous outcomes were expressed in relative risk (RR) with their $95 \%$ confidence interval (CI) values. Statistical significance was assessed using $Z$ test, and the pooled data were considered to be statistically significant at $p<0.05$.

\section{Results}

Our (Zhu and $\mathrm{Wu})$ preliminary search revealed 70 relevant studies, and 61 of them were eventually excluded because they were merely narrative studies or case reports or did not evaluate the surgical outcomes that were the focus of this review. Figure 1 shows details of study identification, inclusion and exclusion. A total of nine articles were involved in our meta-analysis.

\section{Characteristics of studies}

All nine clinical trials [3-11] compared thoracoscopic or laparoscopic (only four laparoscopic cases) repair of CHD with open techniques. All the studies were non-randomized historical control trials. Table 1 shows the detail information of all the trials.

\section{Surgical outcomes}

Our meta-analysis revealed a significantly lower rate of post-operative death in the MIS group than in the open

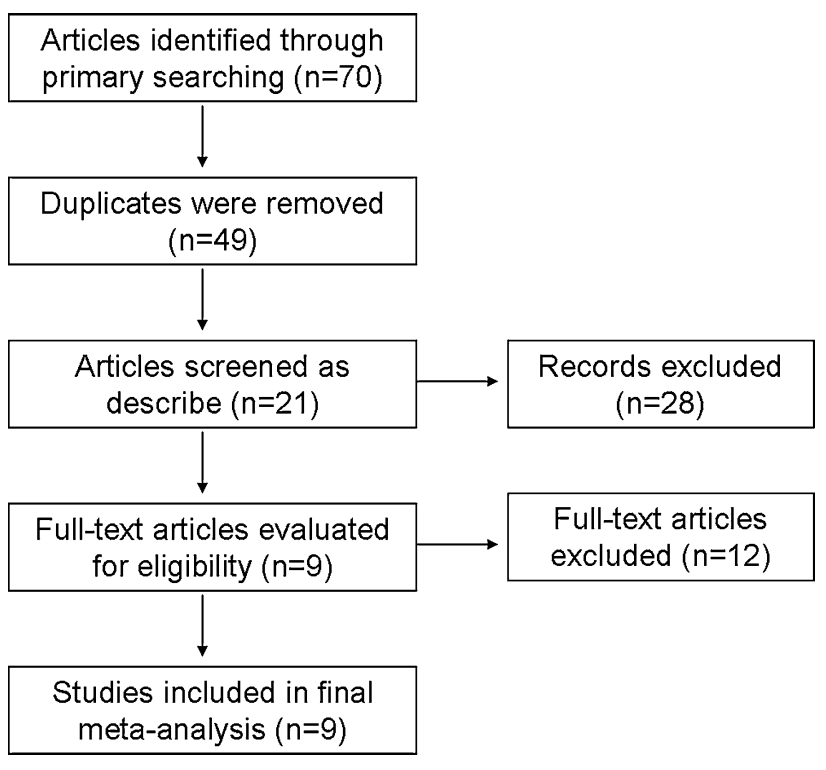

Fig. 1 Flow of study identification, inclusion and exclusion

techniques group with an RR of 0.26 (95\% CI 0.10-0.68; $p=0.006$ ) (Fig. 2). The incidence of hernia recurrence was greater in the MIS group with an RR of $3.42(95 \% \mathrm{CI}$ $1.98-5.88 ; p<0.00001$ ) (Fig. 3). The previous two sets of pooled data both showed good homogeneity among the involved trials. Thus, fixed models were applied for analysis. No significant difference was found for the rates of prosthetic patch use between the two groups (Fig. 4). Fewer cases of surgical complications were found for neonates who underwent thoracoscopic or laparoscopic procedures with an RR of 0.66 (95\% CI 0.47-0.94; $p=0.02$ ) (Fig. 5).

\section{Discussion}

The use of minimally invasive techniques in pediatric surgery has been increasing in the last decade [12]. MIS offers several advantages over open surgery, such as quicker recovery and improved cosmetic effect. Although several studies have reported success in thoracoscopic repair of $\mathrm{CDH}$ [2, 13-15], similarities in outcomes of MIS and standard open operation remains unverified.

\section{Surgical technique}

Almost all of the studies we reviewed showed that thoracoscopy is the most common approach of MIS for CDH [3$8,10,11]$. However, some studies used the laparoscopic approach [9]. Szavay et al. reported that the selection criteria for either thoracoscopic or laparoscopic approach depend on the anatomical site of the hernia. They found 
Table 1 Characteristics of the nine trials included in the meta-analysis

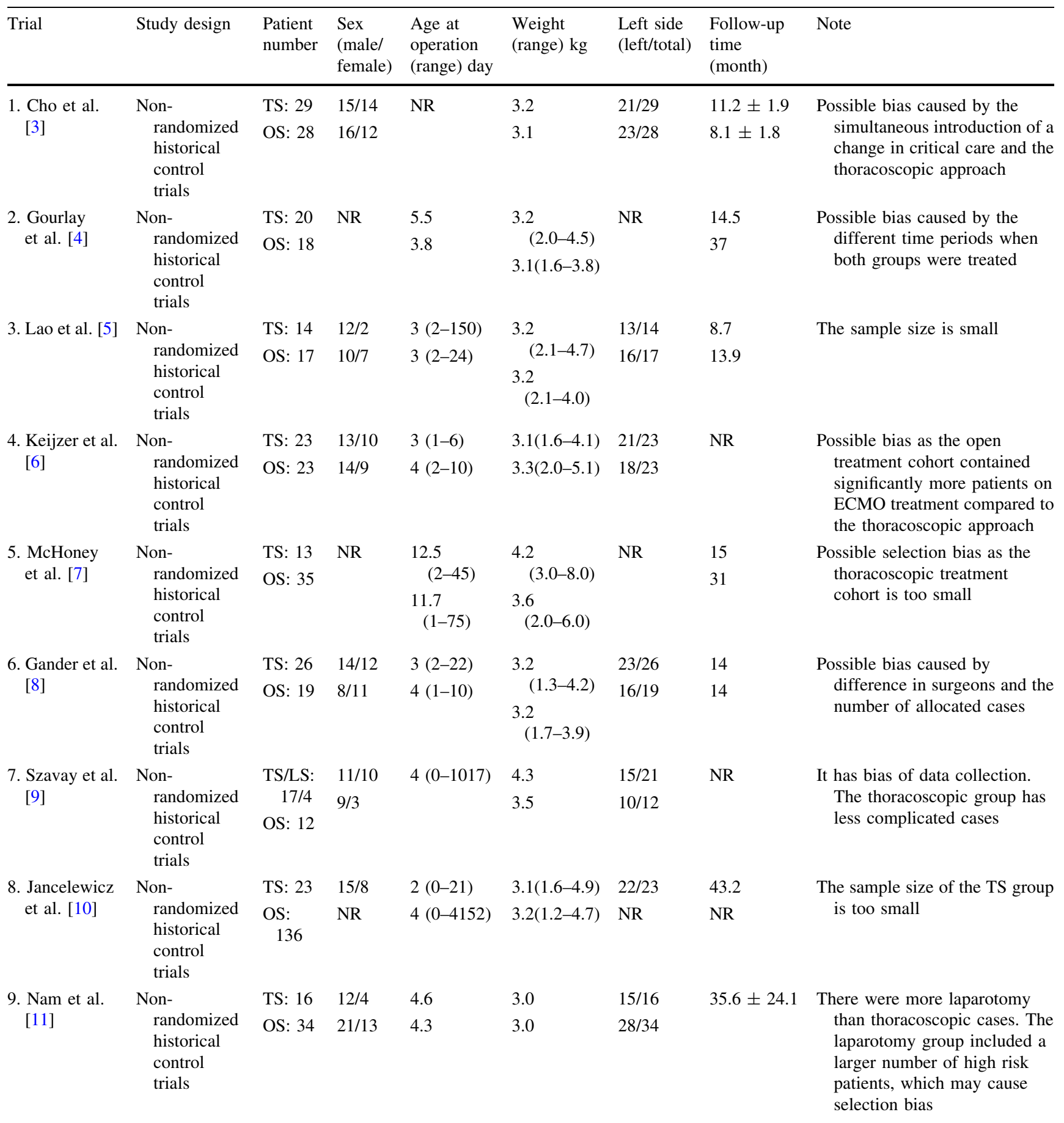

$T S$ thoracoscopic surgery, $O S$ open surgery, $L S$ laparoscopic surgery, $N R$ not report

that the laparoscopic approach is more appropriate for the accessible left-sided ventral hernias (Morgagni's hernia) and proved to be better and easier for abdominal cavity operations [9]. All thoracoscopic repairs were performed on patients in the lateral decubitus position with the affected side elevated, utilizing three to four 3 or $5 \mathrm{~mm}$ ports for access to the thoracic cavity. Insufflation with carbon dioxide was used in most cases, which could also easily facilitate reduction of herniated viscera. Non-absorbable interrupted suture is recommended to close the defect and resection of the hernia sac. Lao et al., Keijzer et al., and Gander et al. reported that patch repair, 


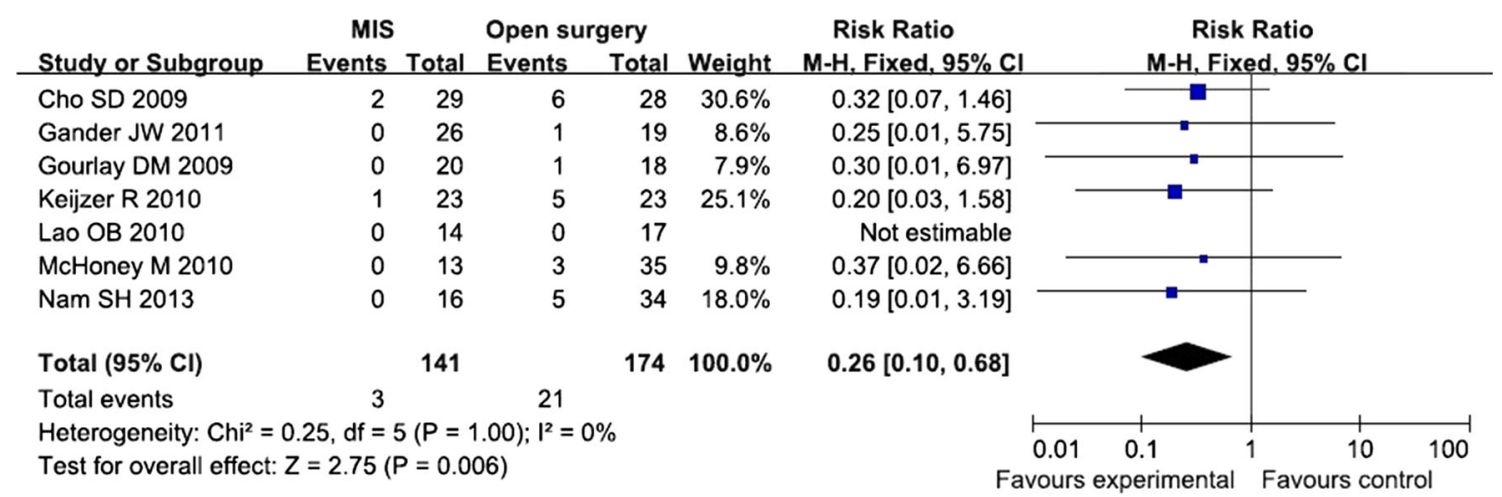

Fig. 2 Forest plot comparing the rates of post-operative death between the MIS and open surgery groups with a fixed effects model

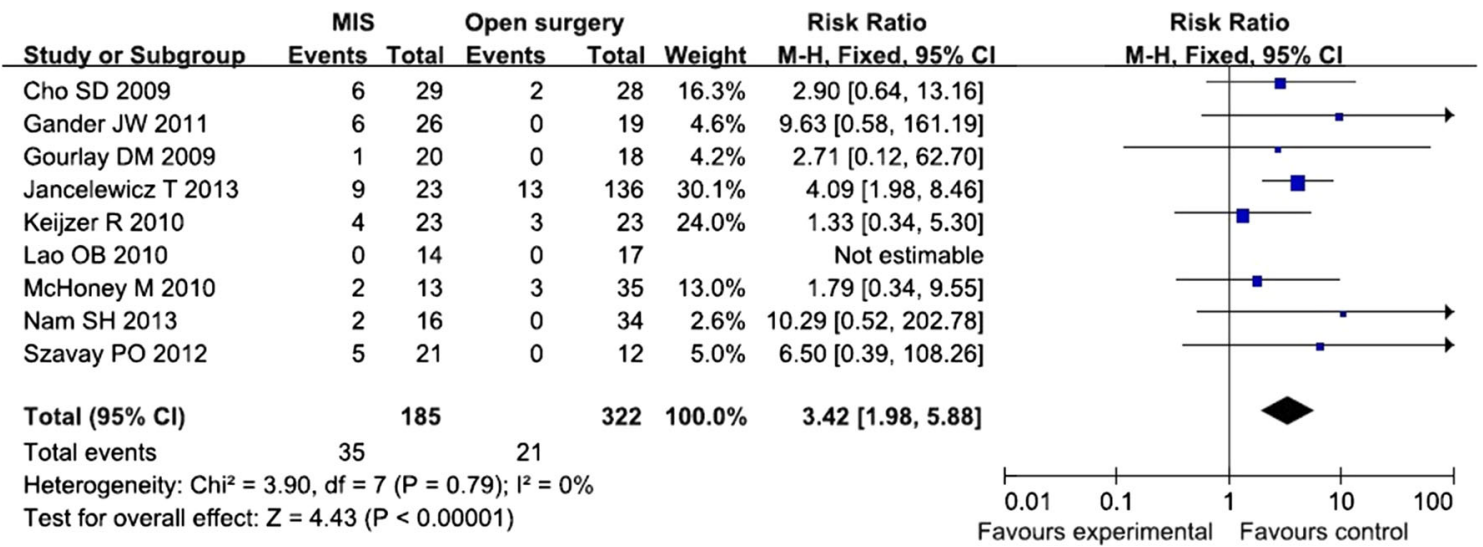

Fig. 3 Forest plot comparing the rates of recurrence between the MIS and open surgery groups with a fixed effects model

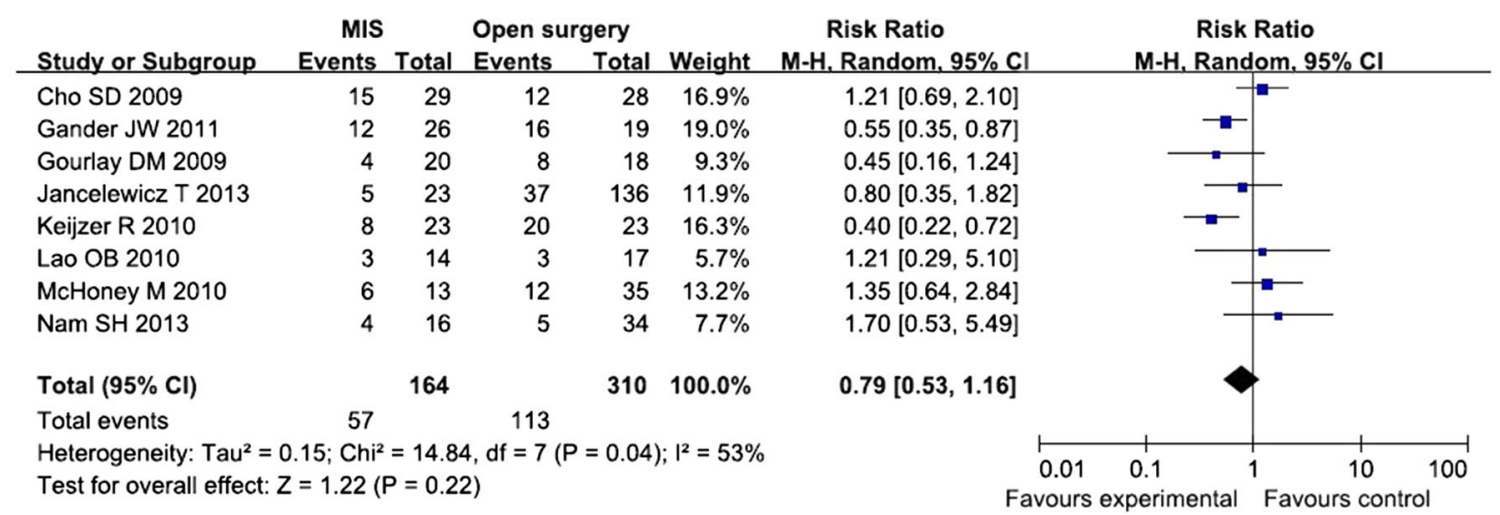

Fig. 4 Forest plot comparing the rates of patch usage between the MIS and open surgery groups with a random effects model

extracorporeal membrane oxygenation (ECMO) treatment, and inability to reduce the herniated intrathoracic abdominal organs are considered as the relative contraindications for thoracoscopic approach [5, 6, 8]. Yang et al. also reported herniation of the stomach into the thorax as indicated by nasogastric tube position in the thorax on a chest film as contraindication for the thoracoscopic repair of $\mathrm{CDH}$ [13]. However, we considered that given the eventual increase in experience with the thoracoscopic approach over time, indications for the thoracoscopic approach should be broadened. According to our result, which showed no significant difference for the rates of prosthetic patch use between the two groups, patch repair could be accomplished by thoracoscopic approach. In some institutions, prior need for ECMO support, mild persistent pulmonary hypertension, prematurity, low birth weight, 


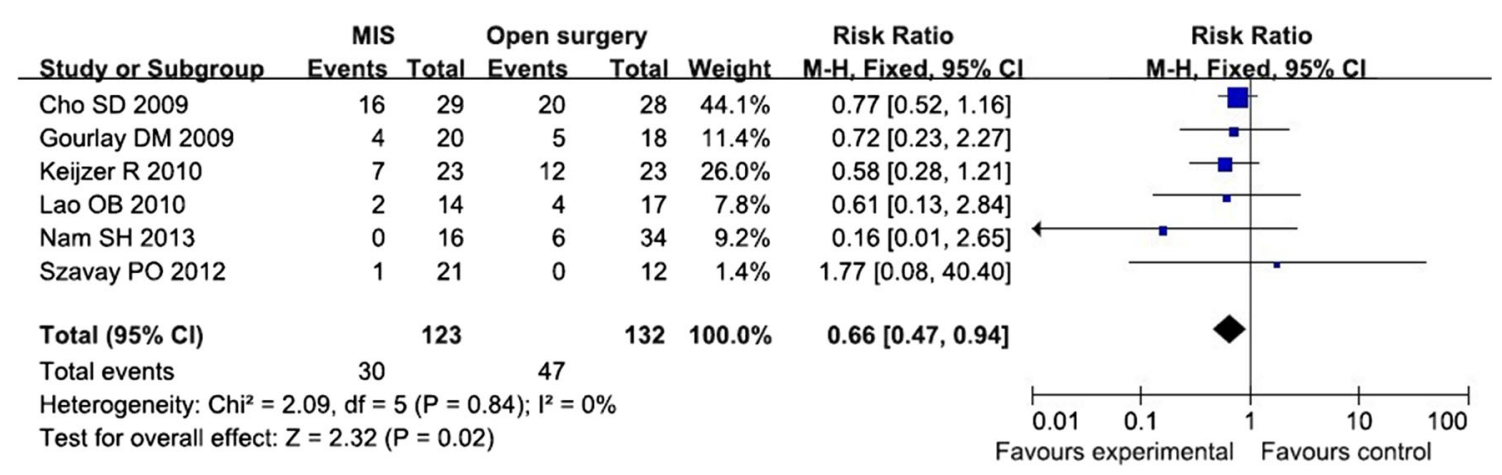

Fig. 5 Forest plot comparing the rates of surgical complications between the MIS and open surgery groups with a fixed effects model

and even diaphragmatic agenesis are not considered as contraindications [3]. Currently, the standard care applied is to close large defects using prosthetic patch [16]. Although six of the nine trials revealed longer operative time for the MIS group than the open surgical group, we considered that duration is not related with intraoperative differences in blood loss, transfusion, or patch use. Duration of the operation is reflective of the learning curve on new endoscopic techniques. In most of the articles we reviewed, the operative times gradually decrease with increased experience and refinements in the technique, which had been described by Cho et al. [3].

Rate of prosthetic patch use varied among the trials involved in this analysis for both the MIS and open surgical groups. The meta-analysis revealed no significant difference between the two groups, and high heterogeneity was found among the groups. Different surgical habits might contribute to this disparity. As previously discussed, learning curves of MIS procedures also affect patient selection for patch use. The use of prosthetic patches became controversial because it was associated with a higher rate of recurrence $[3,9]$. Conclusion could only be drawn if patch use predisposes the patient to a higher rate of recurrence and when the same criteria are applied for patients who underwent MIS.

\section{Complication}

Theoretically, death and recurrence are both post-operative complications. Although the last meta-analysis fails to show a significant difference in survival between endosurgical and open $\mathrm{CDH}$ repair [17], our result show a significantly lower rate of post-operative death in the MIS group than in the open techniques group. But we still agree with the previous comments, because this result may be caused by vulnerability to selection and performance bias. For example, surgeons may have favored open surgery for higher risk, more unstable cases. Eight of the nine trials revealed a significantly higher recurrence rate in the MIS group than in the open surgical group. Our pooled data showed an overall recurrence of $18.9 \%$ (35 of 185) for patients who underwent MIS compared with $6.5 \%$ (21 of 322 ) for patients who underwent open procedures. Our results were consistent with that of a previous meta-analysis [17]. Several factors might contribute to this clinical outcome. As a newly introduced surgical technique, learning curves could not be avoided during the clinical practice of surgeons with limited experience. Jancelewicz et al. reported that for primary thoracoscopic repair, a trend toward decreased recurrence rate is observed from $50 \%$ prior to the year 2008 to $25 \%$ thereafter [10]. Different rates of prosthetic patch use influenced surgical outcomes, including the recurrence rates. However, these explanations are not firmly supported in the patient series. One author performed a comparative analysis on the potential factors involved in post-operative recurrence, such as perinatal conditions, blood gas parameters, and patch use, but none of the clinical data seemed to be predictive of recurrence [8].

All the trials included are susceptible to the limitations of any retrospective review. They all have selection bias, and the numbers of patients are all small to draw a definitive conclusion. Therefore, our meta-analysis also has limitations which are caused by the bias of the included trials. The data we extracted from different retrospective trials, for example, the different follow-up time may raise the possibility of measurement error.

\section{Conclusion}

MIS for CDH repair is associated with lower post-operative mortality and morbidity compared with traditional open surgery. Although the rate of patch use appears to be comparable, the increased risk of recurrence of $\mathrm{CDH}$ should not be ignored. The lack of well-controlled prospective clinical trials might also be a reason for the inability to find significant predictive factors. High-quality 
prospective clinical trials are needed to evaluate these two surgical techniques.

\section{Compliance with ethical standards}

Conflict of interest YZ declares no conflict of interest.

YW declares no conflict of interest.

QP declares no conflict of interest.

LM declares no conflict of interest.

HL declares no conflict of interest.

LL declares no conflict of interest.

Open Access This article is distributed under the terms of the Creative Commons Attribution-NonCommercial 4.0 International License (http://creativecommons.org/licenses/by-nc/4.0/), which permits any noncommercial use, distribution, and reproduction in any medium, provided you give appropriate credit to the original author(s) and the source, provide a link to the Creative Commons license, and indicate if changes were made.

\section{References}

1. Langham MR Jr, Kays DW, Ledbetter DJ, Frentzen B, Sanford LL, Richards DS (1996) Congenital diaphragmatic hernia. Epidemiology and outcome. Clin Perinatol 23:671-688

2. Silen ML, Canvasser DA, Kurkchubasche AG, Andrus CH, Naunheim KS (1995) Video-assisted thoracic surgical repair of a foramen of Bochdalek hernia. Ann Thorac Surg 60:448-450

3. Cho SD, Krishnaswami S, Mckee JC, Zallen G, Silen ML, Bliss DW (2009) Analysis of 29 consecutive thoracoscopic repairs of congenital diaphragmatic hernia in neonates compared to historical controls. J Pediatr Surg 44:80-86

4. Gourlay DM, Cassidy LD, Sato TT, Lal DR, Arca MJ (2009) Beyond feasibility: a comparison of newborns undergoing thoracoscopic and open repair of congenital diaphragmatic hernias. J Pediatr Surg 44:1702-1707

5. Lao OB, Crouthamel MR, Goldin AB, Sawin RS, Waldhausen JH, Kim SS (2010) Thoracoscopic repair of congenital diaphragmatic hernia in infancy. J Laparoendosc Adv Surg Tech A 20:271-276

6. Keijzer R, van de Ven C, Vlot J, Sloots C, Madern G, Tibboel D, Bax K (2010) Thoracoscopic repair in congenital diaphragmatic hernia: patching is safe and reduces the recurrence rate. J Pediatr Surg 45:953-957

7. McHoney M, Giacomello L, Nah SA, De Coppi P, Kiely EM, Curry JI, Drake DP, Eaton S, Pierro A (2010) Thoracoscopic repair of congenital diaphragmatic hernia: intraoperative ventilation and recurrence. J Pediatr Surg 45:355-359

8. Gander JW, Fisher JC, Gross ER, Reichstein AR, Cowles RA, Aspelund G, Stolar CJ, Kuenzler KA (2011) Early recurrence of congenital diaphragmatic hernia is higher after thoracoscopic than open repair: a single institutional study. J Pediatr Surg 46:1303-1308

9. Szavay PO, Obermayr F, Maas C, Luenig H, Blumenstock G, Fuchs J (2012) Perioperative outcome of patients with congenital diaphragmatic hernia undergoing open versus minimally invasive surgery. J Laparoendosc Adv Surg Tech A 22:285-289

10. Jancelewicz T, Langer JC, Chiang M, Bonnard A, Zamakhshary M, Chiu PP (2013) Thoracoscopic repair of neonatal congenital diaphragmatic hernia $(\mathrm{CDH})$ : outcomes after a systematic quality improvement process. J Pediatr Surg 48:321-325

11. Nam SH, Cho MJ, Kim DY, Kim SC (2013) Shifting from laparotomy to thoracoscopic repair of congenital diaphragmatic hernia in neonates: early experience. World J Surg 37:2711-2716

12. Ponsky TA, Rothenberg SS (2008) Minimally invasive surgery in infants less than $5 \mathrm{~kg}$ : experience of 649 cases. Surg Endosc 22:2214-2219

13. Yang EY, Allmendinger N, Johnson SM, Chen C, Wilson JM, Fishman SJ (2005) Neonatal thoracoscopic repair of congenital diaphragmatic hernia: selection criteria for successful outcome. J Pediatr Surg 40:1369-1375

14. Liem NT (2003) Thoracoscopic surgery for congenital diaphragmatic hernia: a report of nine cases. Asian J Surg 26:210-212

15. Arca MJ, Barnhart DC, Lelli JL Jr, Greenfeld J, Harmon CM, Hirschl RB, Teitelbaum DH (2003) Early experience with minimally invasive repair of congenital diaphragmatic hernias: results and lessons learned. J Pediatr Surg 38:1563-1568

16. Moss RL, Chen CM, Harrison MR (2011) Prosthetic patch durability in congenital diaphragmatic hernia: a long-term follow-up study. J Pediatr Surg 36:152-154

17. Lansdale N, Alam S, Losty PD, Jesudason EC (2010) Neonatal endosurgical congenital diaphragmatic hernia repair: a systematic review and meta-analysis. Ann Surg 252:20-26 